\title{
Hydrochemical changes induced by underground pumped storage hydropower: influence of aquifer parameters in coal mine environments
}

\author{
Estanislao Pujades ${ }^{1}$, Anna Jurado ${ }^{2}$, Philippe Orban $^{3}$, and Alain Dassargues ${ }^{3}$ \\ ${ }^{1}$ Department of Computational Hydrosystems, UFZ - Helmholtz Centre for Environmental Research, \\ Permoserstr. 15, 04318 Leipzig, Germany \\ ${ }^{2}$ Institute for Groundwater Management, Technische Universität Dresden, 01062 Dresden, Germany \\ ${ }^{3}$ Hydrogeology and Environmental Geology, Urban \& Environmental Eng., University of Liege, 4000 Liege, Belgium
}

Correspondence: Estanislao Pujades (estanislao.pujades@gmail.com, estanislao.pujades-garnes@ufz.de)

Received: 31 May 2018 - Accepted: 12 July 2018 - Published: 26 July 2018

\begin{abstract}
Underground pumped storage hydropower (UPSH) induces hydrochemical changes when water evolves to reach equilibrium with the atmosphere (in the surface reservoir) and with the surrounding medium (in the underground reservoir). These hydrochemical changes may impact the environment and the efficiency of the system (i.e., the UPSH plant), especially in coal mine environments where the presence of sulphide minerals is common. For this reason, it is needed to assess the variables that control the behavior of the system in order to establish criteria for the selection of abandoned mines to be used as underground reservoirs in future UPSH plants.

Coupled hydro-chemical numerical models are used for investigating the influence of hydraulic parameters on the hydrochemical changes when pyrite is present in the surrounding medium. Results show the role of the hydraulic conductivity and the porosity on the system behavior, which is helpful for selecting those abandoned mines where the hydrochemical changes and their associated consequences will be less.
\end{abstract}

\section{Introduction}

Underground pumped storage hydropower (UPSH) is an alternative energy storage system (ESS) for flat regions (Pujades et al., 2016; Pummer and Schüttrumpf, 2018). UPSH plants consist in two reservoirs, one is underground while the other is located at the surface (Barnes and Levine, 2011). The excess of electricity generated during low demand energy pe- riods is used for pumping water from the underground to the surface reservoir, and when the demand of energy increases, water is released into the underground reservoir through turbines for generating electricity. Although there are not bibliographical evidences of UPSH constructed plants, this technology has been investigated in different parts of the world: the Netherlands (Min, 1984), Singapore (Wong, 1996), USA (Allen et al., 1984; Severson, 2011), Germany (Beck and Schmidt, 2011; Zillman and Perau, 2015; Alvarado et al., 2016), Belgium (Bodeux et al., 2016; Poulain et al., 2018), Spain (Menéndez et al., 2017) and South Africa (Winde and Stoch, 2010a, b; Khan and Davidson, 2016; Winde et al., 2017), Finland and Australia (Academy of Science of South Africa, 2016).

Although it would be possible to drill the underground reservoir, the alternative considered in this paper, which may be more efficient and have positive effects for local communities after the cessation of mine activities, would consist in re-using abandoned mines. The main concern of UPSH using abandoned mines is the water exchanges between the underground reservoir and the surrounding porous medium because they can affect the environment and the efficiency of the UPSH plant. Most studies focused on water exchanges consider flow related issues (Bodeux et al., 2017; Pujades et al., 2017a). However, recently, Pujades et al. (2017b) have suggested the importance of considering hydrochemical changes induced by UPSH plants. These changes may impact on the environment and affect the efficiency of the plant. 

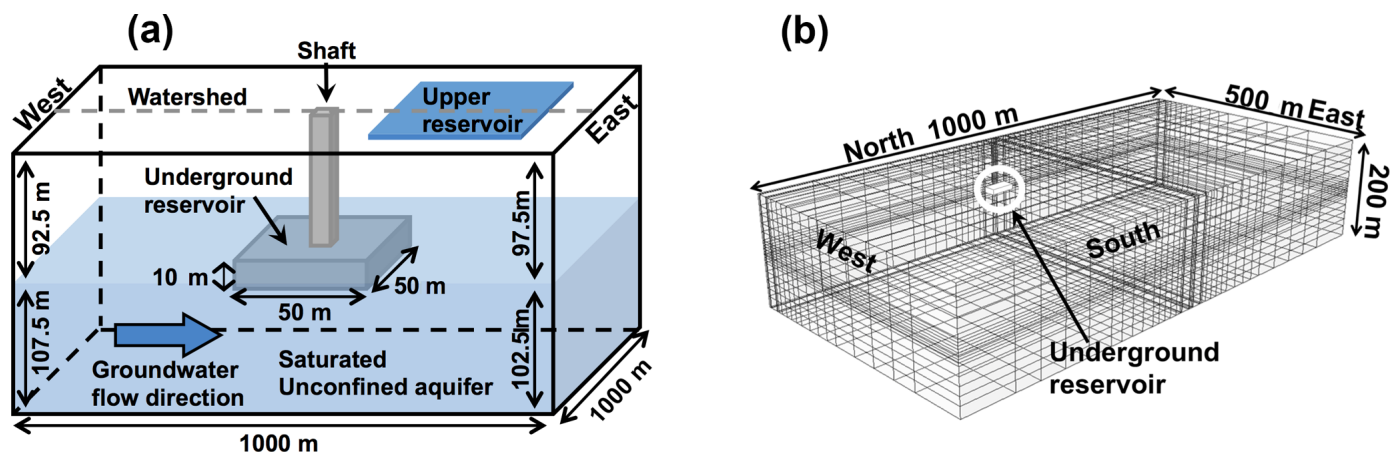

Figure 1. General view of the problem (a) and the whole modelled domain (b).

Water is aerated when it is pumped, discharged and stored in the surface reservoir. As a result, its chemistry evolves to reach equilibrium with the atmosphere. Similarly, when water is discharged into the underground reservoir, its chemistry evolves to reach equilibrium with the surrounding porous medium. These hydrochemical changes may produce $\mathrm{pH}$ variations, especially in coal mine contexts where pyrite is a common mineral. Its oxidation leads to $\mathrm{pH}$ lowering. Low $\mathrm{pH}$ values would affect the environment (decreasing the quality of groundwater and surface water bodies) and the efficiency of the plant (corroding UPSH facilities such as pipes, turbines, pumps or concrete structures).

Although the general behaviour of the system has been previously stated (Pujades et al., 2018), there is not any study in which the influence of the aquifer hydraulic parameters on a UPSH system is assessed. To establish the role of aquifer hydraulic parameters will be meaningful for selecting the most suitable places where constructing future UPSH plants. Thus, the main objective of this work is to investigate the importance of the hydraulic parameters on the $\mathrm{pH}$ variations occurring when abandoned coal mines (with presence of pyrite) are used for UPSH.

\section{Methods}

\subsection{Problem statement}

A $200 \mathrm{~m}$ thick domain with an underground reservoir in the middle is considered (Fig. 1a). The reservoir $(50 \times 50 \mathrm{~m}$ and $10 \mathrm{~m}$ of height) is saturated in natural conditions with the top and bottom located respectively at 95 and $105 \mathrm{~m}$ depth. The water table is located at 92.5 and $97.5 \mathrm{~m}$ depth in the upgradient and downgradient boundaries, respectively. Thus, the underground reservoir is located at the top of an unconfined porous medium whose saturated thickness ranges between 107.5 and $102.5 \mathrm{~m}$. The outer boundaries are located at $500 \mathrm{~m}$ from the underground reservoir. The hydraulic gradient under natural conditions is 0.005 .

Frequency of pumping and discharging phases is chosen according to day/night cycles (i.e., $12 \mathrm{~h}$ pumping and
$12 \mathrm{~h}$ discharging water). Pumping and discharging rates are $43000 \mathrm{~m}^{3} \mathrm{~d}^{-1}$. These rates allow decreasing and increasing the hydraulic head inside the underground reservoir up to $8.6 \mathrm{~m}$ during each pumping-discharging cycle.

It is assumed that the modelled cavity belongs to an abandoned coal mine. Coal deposits usually contain sulphide minerals, whose oxidation may entail important consequences for water chemistry. Pyrite is the most common sulphide mineral in this kind of deposits (Akcil and Koldas, 2006), and thus, it is assumed that the porous medium contains $1 \%$ pyrite. Reaction rates for the other minerals (e.g. silicates) are assumed very low (White and Brantley, 1995), and are neglected.

\subsection{Numerical model}

The code PHAST (Parkhurst et al., 1995; Parkhurst and Kipp, 2002) is used to simulate the problem. This code solves multicomponent, reactive solute transport in threedimensional saturated groundwater flow (Parkhurst et al., 2010). The watershed divide crossing the domain from the west to the east boundaries (Fig. 1a) allows modeling only half of the domain without affecting the results. The modeled "half-domain" is divided in 15600 elements whose size ranges from 2 to $100 \mathrm{~m}$ (they are refined towards the underground reservoir) (Fig. 1). Dirichlet boundary conditions (BCs) are implemented in the west and east boundaries with head prescribed at 92.5 and $97.5 \mathrm{~m}$ depth, respectively. Flow-rate BCs are adopted in nodes located inside the underground reservoir for simulating the pumpings and discharges. The values of longitudinal $\left(\alpha_{\mathrm{L}}\right)$ and transversal $\left(\alpha_{\mathrm{T}}\right)$ dispersivity are 10 and $1 \mathrm{~m}$, respectively. The underground reservoir is modelled by implementing a high value of $K$ $\left(10^{6} \mathrm{~m} \mathrm{~d}^{-1}\right), S$ of 1 , and a dispersivity of $10^{4} \mathrm{~m}$ in the three directions. The validity of the assumptions adopted for modelling the underground reservoir has been evaluated by $\mathrm{Pu}-$ jades et al. (2017b). Three different scenarios (Sce1, Sce2 and Sce3) are simulated and compared to ascertain the influence of the hydraulic conductivity $(K)$ and porosity $(\Phi)$ values in the surrounding porous medium on the system behaviour. $K$ and $\Phi$ are $0.01 \mathrm{~m} \mathrm{~d}^{-1}$ and 0.05 , respectively, in 

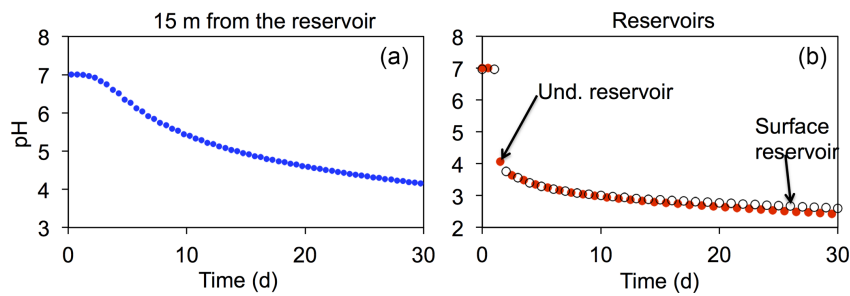

Figure 2. $\mathrm{pH}$ evolution in the surrounding porous medium at $15 \mathrm{~m}$ from the underground reservoir (a). $\mathrm{pH}$ evolution in the reservoirs (b). These results are obtained for Sce1.

Sce1. $K$ is increased in Sce2 up to $0.1 \mathrm{md}^{-1}$, while $\Phi$ is increased in Sce3 to 0.25 . The hydraulic parameters $(K$ and $\Phi)$ remain constant during the simulated period. This particularity does not affect noticeably the results because the variation of $\Phi$ is negligible (Pujades et al., 2018).

\subsection{Basic concepts}

Pujades et al. (2018) stated the main trends of the system. Dissolved oxygen increases when the water is pumped, discharged and stored in the surface reservoir. When this water is discharged in the underground reservoir and is exchanged with the surrounding porous medium, it oxidizes pyrite decreasing the groundwater $\mathrm{pH}$ (Fig. 2). Pyrite is oxidized until all available oxygen is consumed. Subsequently, water is pumped, discharged and stored in the surface reservoir and the dissolved oxygen increases again. $\mathrm{pH}$ in the underground reservoir decreases when it is filled with groundwater from the surrounding porous medium (Fig. 2). As a result, when this water is pumped to the surface reservoir, $\mathrm{pH}$ also decreases on it. In addition, minerals such as ferrihydrite, goethite and schwermannite may precipitate in the surface reservoir contributing also to the $\mathrm{pH}$ reduction.

\section{Results}

Results show the differences in percentage between Sce1 and the scenarios Sce2 and Sce3. A positive difference means that computed results (for Sce2 and Sce3) are higher than those obtained for Sce1 while differences are negative when they are lower.

\subsection{Underground and surface reservoirs}

Figure 3 shows the results concerning the $\mathrm{pH}$ evolution in the surface (left) and underground reservoirs (right). $\mathrm{pH}$ is higher for both scenarios (Sce2 and Sce3) than that computed for Sce1. pH decreases less for Sce2 and Sce3 than for Scel because the volume of groundwater reaching the reservoir from the upgradient side, which is less affected by the pyrite oxidation, increases when the values of $K$ and $\Phi$ are incremented. In principle, $\mathrm{pH}$ difference should increase
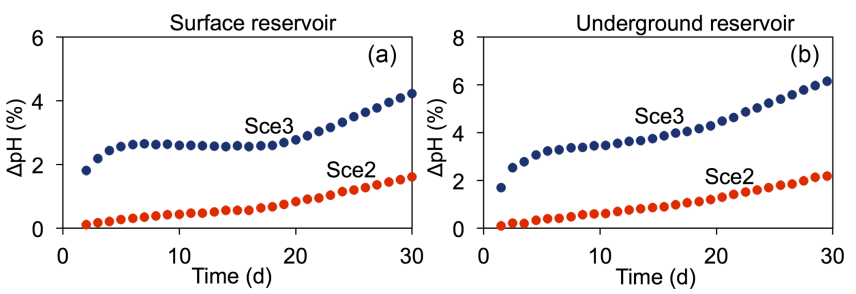

Figure 3. $\mathrm{pH}$ differences in the surface (a) and underground reservoirs (b).

constantly with time as the volume of water reaching the underground reservoir from the upgradient side. However, after an initial increase, the $\mathrm{pH}$ difference remains nearly constant, especially between Sce3 and Sce1, and the $\mathrm{pH}$ difference with respect Sce1 only start to increase constantly after 20 simulated days. This behaviour may be related with the precipitation of schwertmannite in the surface reservoir, which releases $\mathrm{H}^{+}$(i.e., reduces the $\mathrm{pH}$ ). In addition, the precipitation rate of schwertmannite decreases with $\mathrm{pH}$ and stops for $\mathrm{pH}$ values lower than 2.8. Therefore, given that $\mathrm{pH}$ in Sce2 and Sce3 are higher than in Sce1, more schwertmannite precipitates, which contribute to decrease the $\mathrm{pH}$ and avoid a constant increase of the $\mathrm{pH}$ difference between scenarios. However, after 20 days, the precipitation of schwertmannite stops and $\mathrm{pH}$ difference between scenarios only depend on the groundwater reaching the reservoir from the upgradient side. As a result, the $\mathrm{pH}$ difference starts to increase constantly.

\subsection{Surrounding medium}

Figure 4 shows the results concerning the $\mathrm{pH}$ evolution in the surrounding porous medium. $\mathrm{pH}$ is computed at a distance of $15 \mathrm{~m}$ from the underground reservoir (in the downgradient side). In Sce2, pH is lower than that for Sce1 because dissolved oxygen reaches faster the surrounding medium (dissolving more pyrite) and groundwater with low $\mathrm{pH}$ flows faster until the distance at which the $\mathrm{pH}$ is computed. Contrarily, $\mathrm{pH}$ decreases less for Sce3 than in Sce1 although the water exchanges increase and the dissolved oxygen reaches faster the surrounding medium. In this case (Sce3), the volume of water in the aquifer is higher than that of Sce1 and the $\mathrm{pH}$ reduction is buffered (i.e., there is a dilution effect).

\section{Conclusions}

This work investigates the influence of the hydraulic conductivity and the porosity on the hydrochemical changes induced by UPSH. Results could be helpful for defining screening strategies, which should be used for the selection of potential abandoned coal mines to construct future UPSH plants.

Results show that $\mathrm{pH}$ decreases less in the reservoirs but more in the surrounding porous medium when the value of $K$ 


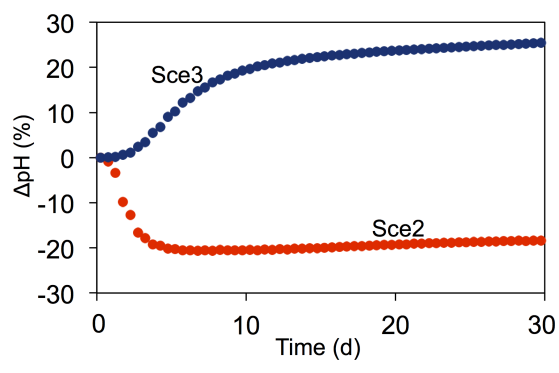

Figure 4. $\mathrm{pH}$ differences in the surrounding porous medium. $\mathrm{pH}$ is computed $15 \mathrm{~m}$ far away from the underground reservoir in the downstream direction.

is raised. This behaviour in the reservoirs is positive for mitigating corrosion problems in the plant facilities (e.g., pipes, turbines, pumps) and the environmental impact if some water from the surface reservoir is accidentally discharged in surface water bodies. However, the mitigation of the corrosion and environmental impact in surface water bodies would be very limited since $\mathrm{pH}$ difference between Sce2 and Sce1 in the reservoirs are lower than $5 \%$. Contrary, the $\mathrm{pH}$ decreases approximately the $20 \%$ in comparison with Sce1 in the surrounding porous medium, which would increase the environmental impact on groundwater. Given these results, coal mines surrounded by materials with low values of $K$ would be preferable for mitigating the environmental impact.

A different behaviour is observed when porosity is increased. In this case, $\mathrm{pH}$ decreases less in the reservoirs and also in the surrounding porous medium. In that particular case, the adverse effects of UPSH in the presence of pyrite would be mitigated. Thus, coal mines surrounded by materials with high values of porosity would be preferable for constructing UPSH plants.

Data availability. Data containing the numerical results presented in this article are openly available in Open Science Framework at http://doi.org/10.17605/OSF.IO/BCN7K (Pujades, 2018).

Competing interests. The authors declare that they have no conflict of interest.

Special issue statement. This article is part of the special issue "European Geosciences Union General Assembly 2018, EGU Division Energy, Resources \& Environment (ERE)". It is a result of the EGU General Assembly 2018, Vienna, Austria, 8-13 April 2018.

Acknowledgements. Estanislao Pujades and Anna Jurado gratefully acknowledge the financial support from the University of Liège and the EU through the Marie Curie BeIPD-COFUND postdoctoral fellowship programme (2014-2016 and 2015-2017 "Fellows from FP7-MSCA-COFUND, 600405"). This research was supported by the Public Service of Wallonia - Department of Energy and Sustainable Building through the Smartwater project.

The article processing charges for this open-access

publication were covered by a Research

Centre of the Helmholtz Association.

Edited by: Luke Griffiths

Reviewed by: Mauro Cacace and one anonymous referee

\section{References}

Academy of Science of South Africa: Science Business Society Dialogue Conference: Strengthening the Science Business Society Dialogue in the SADC Region, Johannesburg, South Africa, 2830 November 2017, 2018.

Akcil, A. and Koldas, S.: Acid Mine Drainage (AMD): causes, treatment and case studies, Improving Environmental, Economic and Ethical Performance in the Mining Industry - Part 2, Life cycle and process analysis and technical issues, J. Clean. Prod., 14, 1139-1145, https://doi.org/10.1016/j.jclepro.2004.09.006, 2006.

Allen, R. D., Doherty, T. J., and Kannberg, L. D.: Underground pumped hydroelectric storage, Pacific Northwest Lab., Richland, WA, USA, Report No.: PNL-5142, 78 pp., https://doi.org/10.2172/6517343, 1984.

Alvarado, R., Niemann, A., and Wortberg, T.: Underground Pumped-Storage Hydroelectricity using existing Coal Mining Infrastructure, in: E-proceedings of the 36th IAHR World Congress, The Hague, the Netherlands, 28 June-3 July 2015, 2016.

Beck, H. P. and Schmidt, M.: Windenergiespeicherung durch Nachnutzung stillgelegter Bergwerke, Clausthal-Zellerfeld, Univ.Bibliothek Clausthal, 2011.

Barnes, F. S. and Levine, J. G. (Eds.): Large Energy Storage Systems Handbook, CRC Press, Boca Raton, USA, 2011.

Bodeux, S., Pujades, E., Orban, P., Brouyère, S., and Dassargues, A.: How groundwater interactions can influence UPSH (Underground Pumping Storage Hydroelectricity) operations, in: Sustainable Hydraulics in the Era of Global Change, CRC Press, London, UK, 973-973, 2016.

Bodeux, S., Pujades, E., Orban, P., Brouyère, S., and Dassargues, A.: Interactions between groundwater and the cavity of an old slate mine used as lower reservoir of an UPSH (Underground Pumped Storage Hydroelectricity): A modelling approach, Eng. Geol., 217, 71-80, https://doi.org/10.1016/j.enggeo.2016.12.007, 2017.

Khan, S. Y. and Davidson, I. E.: Underground Pumped Hydroelectric Energy Storage in South Africa using Aquifers and Existing Infrastructure, in: NEIS Conference 2016, Springer Vieweg, Wiesbaden, 119-122, 2017.

Menéndez, J., Loredo, J., Fernandez, J. M., and Galdo, M.: Underground pumped-storage hydro power plants with mine water in abandoned coal mines in northern Spain, in: Mine Water \& Circular Economy, edited by: Wolkersdorfer, C., Sartz, L., Sillanpää, M., and Häkkinen, A., 1, 6-14, Lappeenranta University of Technology, Lappeenranta, Finland, 2017.

Min, A. P. N.: Ondergrondse Pomp Accumulatie Centrale: Effectiviteitsverbetering d.m.v. verschillende pomp- 
turbinevermogens, MS thesis, Delft University of Technology, the Netherlands, 147 pp., 1984.

Parkhurst, D. L.: User's quide to PHREEQC - a computer program for speciation, reaction-path, advective transport, and inverse geochemical calculations, US Geological Survey, Water Resources Investigations, Report 95-4227, 143 pp., 1995.

Parkhurst, D. L. and Kipp, K. L.: Parallel processing for PHAST: a three-dimensional reactive-transport simulator, in: Proceedings of the XIVth International Conference on Computational Methods in Water Resources (CMWR XIV), 23-28 June 2002, Delft, the Netherlands, 711-718, https://doi.org/10.1016/S01675648(02)80128-9, 2002.

Parkhurst, D. L., Kipp, K. L., and Charlton, S. R.: PHAST Version 2 - A Program for Simulating Groundwater Flow, Solute Transport, and Multicomponent Geochemical Reactions, U.S. Geological Survey Techniques and Methods, 6-A35, 235 pp., 2010.

Poulain, A., De Dreuzy, J. R., and Goderniaux, P.: Pump Hydro Energy Storage systems (PHES) in groundwater flooded quarries, J. Hydrol., 559, 1002-1012, 2018.

Pujades, E.: Numerical Data: Hydrochemical Changes in UPSH, Influence of Hydraulic Parameters, Open Science Framework, https://doi.org/10.17605/OSF.IO/BCN7K, 2018.

Pujades, E., Willems, T., Bodeux, S., Orban, P., and Dassargues, A.: Underground pumped storage hydroelectricity using abandoned works (deep mines or open pits) and the impact on groundwater flow, Hydrogeol. J., 24, 1531-1546, https://doi.org/10.1007/s10040-016-1413-z, 2016.

Pujades, E., Orban, P., Bodeux, S., Archambeau, P., Erpicum, S., and Dassargues, A.: Underground pumped storage hydropower plants using open pit mines: How do groundwater exchanges influence the efficiency?, Appl. Energ., 190, 135-146, https://doi.org/10.1016/j.apenergy.2016.12.093, 2017a.

Pujades, E., Orban, P., Jurado, A., Ayora, C., Brouyère, S., and Dassargues, A.: Water chemical evolution in Underground Pumped Storage Hydropower plants and induced consequences, Enrgy. Proced., 125, 504-510, 2017b.

Pujades, E., Jurado, A., Orban, P., Ayora, C., Poulain, A., Goderniaux, P., Brouyère, S., and Dassargues, A.: Hydrochemical changes induced by underground pumped storage hydropower and their associated impacts, J. Hydrol., 563, 927-941, 2018.
Pummer, E. and Schüttrumpf, H.: Reflection Phenomena in Underground Pumped Storage Reservoirs, Water, 10, 504, https://doi.org/10.3390/w10040504, 2018.

Severson, M. J.: Preliminary Evaluation of Establishing an Underground Taconite Mine, to be Used Later as a Lower Reservoir in a Pumped Hydro Energy Storage Facility, on the Mesabi Iron Range, Minnesota, Natural Resources Research Institute, University of Minnesota, Duluth, MN, Report of Investigation NRRI/RI-2011/02, 28 pp., 2011.

White, A. F. and Brantley, S. L.: Chemical weathering rates of silicate mienrals: an overview, Rev. Mineral., 31, 1-21, 1995.

Winde, F. and Stoch, E. J.: Threats and opportunities for postclosure development in dolomitic gold mining areas of the West Rand and Far West Rand (South Africa) - a hydraulic view Part 1: Mining legacy and future threats, Water SA, 36, 69-74, https://doi.org/10.4314/wsa.v36i1.50908, 2010a.

Winde, F. and Stoch, E. J.: Threats and opportunities for postclosure development in dolomitic gold-mining areas of the West Rand and Far West Rand (South Africa) - a hydraulic view Part 2: Opportunities, Water SA, 36, 75-82, https://doi.org/10.4314/wsa.v36i1.50909, 2010b.

Winde, F., Kaiser, F., and Erasmus, E.: Exploring the use of deep level gold mines in South Africa for underground pumped hydroelectric energy storage schemes, Adv. Mater. Res.-Switz., 78, 668-682, 2017.

Wong, I. H.: An underground pumped storage scheme in the Bukit Timah Granite of Singapore, Tunn. Undergr. Sp. Tech., 11, 485489, https://doi.org/10.1016/S0886-7798(96)00035-1, 1996.

Zillmann, A. and Perau, E.: A conceptual analysis for an underground pumped storage plant in rock mass of the Ruhr Region, in: Proceedings of the XVI, European Conference on Soil Mechanics and Geotechnical Engineering (ECSMGE), Edinburgh, Scotland, 13-17 September 2015, ICE Publishing, 3789-3794, available at: https://www.icevirtuallibrary.com/doi/abs/10.1680/ ecsmge.60678.vol7.597 (last access: 23 July 2018), 2015. 